\title{
Effects of Baicalin on Diabetic Cardiac Autonomic Neuropathy Mediated by the P2Y12 Receptor in Rat Stellate Ganglia
}

\author{
Xuan Sheng $^{a}$ Jiayue Wang ${ }^{b}$ Jingjing Guo ${ }^{a}$ Yurong Xua Huaide Jiang ${ }^{a}$ \\ Chaoran Zheng $^{a}$ Zixi Xub Yuanruohan Zhang ${ }^{c}$ Hongyu Che $^{c}$ \\ Shangdong Liang ${ }^{\mathrm{a}}$ Gaochun Zhu ${ }^{\mathrm{d}}$ Guilin Lia \\ aDepartment of Physiology, Medical College of Nanchang University, ${ }^{b}$ Department of the First Clinical, \\ 'Queen Mary School, 'Department of Anatomy, Medical College of Nanchang University, Nanchang, \\ P. R. China
}

\section{Key Words}

Diabetic cardiac autonomic neuropathy $•$ Baicalin $•$ P2Y12 receptor $•$ Stellate ganglia $•$ Satellite glial cells

\begin{abstract}
Background/Aims: Chronic diabetic hyperglycemia can damage various of organ systems and cause serious complications. Although diabetic cardiac autonomic neuropathy (DCAN) is the primary cause of death in diabetic patients, its pathogenesis remains to be fully elucidated. Baicalin is a flavonoid extracted from Scutellaria baicalensis root and has antibacterial, diuretic, anti-inflammatory, anti- metamorphotic, and antispasmodic effects. Our study explored the effects of baicalin on enhancing sympathoexcitatory response induced by DCAN via the P2Y12 receptor. Methods: A type 2 diabetes mellitus rat model was induced by a combination of diet and streptozotocin. Serum epinephrine was measured by enzyme-linked immunosorbent assay. Blood pressure and heart rate were measured using the indirect tail-cuff method. Heart rate variability was analyzed using the frequency-domain of electrocardiogram recordings. The expression levels of P2Y12, interleukin-1beta (IL-1 $\beta$ ), tumor necrosis factor alpha (TNF- $\alpha$ ), and connexin $43(\mathrm{C} \times 43)$ were determined by quantitative real-time reverse transcriptionpolymerase chain reaction and western blotting. The interaction between baicalin and P2Y12 determined using by molecular docking. Results: Baicalin alleviated elevated blood pressure and heart rate, improved heart rate variability, and decreased the elevated expression levels of P2Y12, IL-1 $\beta$, TNF- $\alpha$, and Cx43 in the stellate ganglia of diabetic rats. Baicalin also reduced the elevated concentration of serum epinephrine and the phosphorylation of p38 mitogenactivated protein kinase in diabetic rats. Conclusion: Baicalin decreases sympathetic activity by inhibiting the P2Y12 receptor in stellate ganglia satellite glial cells to maintain the balance between sympathetic and parasympathetic nerves and relieves DCAN in the rat.




\section{Introduction}

With changing dietary habits and lifestyles, the number of diabetic patients is increasing rapidly worldwide. The International Diabetes Federation estimates that the number of people aged 20-79 years with diabetes will rise to 642 million by 2040 [1]. Diabetic cardiac autonomic neuropathy (DCAN) is a relatively common, serious, and often devastating complication of diabetes mellitus (DM). Because the principal control mechanism regulating the heart rate and overall cardiac output is autonomic innervation [2], damage to the autonomic nerve fibers in the heart in DCAN disrupts cardiac control [3].

The autonomic ganglia include sympathetic ganglia and parasympathetic ganglia. Stellate ganglia (SG) are cervical sympathetic ganglia whose nerve fibers reach the cardiac plexus and influence cardiac function [4]. The stellate sympathetic ganglia, which have an integrated function, can accept the afferent signals of diabetic autonomic neuropathy and influence sympathetic efferent activity. SG neurons are surrounded by peripheral satellite glial cells (SGCs), and with close association of SGCs and neurons promoting the bidirectional regulation of SGC function and neuronal excitability [5, 6]. SGCs are an important component of the nociceptive signaling pathway $[5,6]$. During injury and inflammation, over-excited neurons activate SGCs. This activation induces glial cell proliferation and increased expression of glial fibrillary acidic protein (GFAP) and inflammatory mediators [7]. Additionally, peripheral nerve injury triggers an abnormal thickening of SGCs and increases the number of SGC gap junctions.

Adenosine- $5^{\prime}$-triphosphate (ATP) and its breakdown product adenosine diphosphate (ADP) are excitatory neurotransmitters or neuromodulators found throughout the peripheral and central nervous system [8, 9]. P2 receptors are divided into P2X (ligand-gated nonselective cation channel receptor) and P2Y (G-protein coupled receptor) subfamilies [8]. This receptor is a member of the P2Y subfamily and has several biological functions. The P2Y12 receptor, which is expressed on platelets, mediates platelet aggregation and shape [10]. In addition to its role in platelet aggregation, the P2Y12 receptor is also involved in synaptic plasticity [11] as well as cancer [12], inflammatory and neuropathic pain [13]. Application of a selective P2Y12 receptor antagonist or genetic deletion of the P2Y12 receptor alleviates these pain, as well as cytokine production $[12,13]$. Importantly, the P2Y12 receptor is expressed by the SGCs of the SG [5].

Chinese herbal medicine has been widely used to treat DM for many years. Baicalin-a flavone glycoside derived from the root of Scutellaria baicalensis-has anti-oxidative, anti-inflammatory, and anti-apoptotic activities [14-16]. In addition, it attenuates insulin resistance and diabetes-associated cognitive deficits [17-19]. However, it is unclear whether baicalin improves DCAN. Accordingly, the objective of this study was to examine the effects of baicalin on regulation of expression of P2Y12 receptor in the SG and to explore the impact of baicalin on P2Y12 receptor-mediated DCAN in a type 2 DM (T2DM) rat model.

\section{Materials and Methods}

\section{Animal model and groups}

Adult male Sprague-Dawley rats were provided by the Center of Laboratory Animal Science of Nanchang University. The use of animals was reviewed and approved by the Animal Care and Use Committees of Nanchang University Medical Schools. Rats were housed in standard metabolic cages (three rats per cage) and kept at $40-70 \%$ humidity and room temperature $\left(21-25^{\circ} \mathrm{C}\right)$. Control rats (Ctrl) had free access to water and the common diet (which comprised 53\% carbohydrate, $23 \%$ protein, and $5 \%$ fat). The T2DM model was induced by a combination of diet and streptozotocin (STZ) treatment, generating state of islet damage, high sugar levels, and hyperlipidemia [20]. Diabetic rats were fed a homemade high-fat and high-sugar diet (66.5\% basal diet, $20 \%$ sugar, $10 \%$ oil, $2.5 \%$ cholesterol, and 1\% sodium cholate) for 4 weeks. Model rats were injected intraperitoneally with STZ (30 mg/kg) [20], whereas control group rats were injected intraperitoneally with vehicle (citrate buffer, $\mathrm{pH} 4.4$ ). Experimental rats with fasting blood 


\section{Cellular Physiology Cell Physiol Biochem 2018;46:986-998 \begin{tabular}{l|l} 
and Biochemistry Published online: April 17, 2018 & $\begin{array}{l}\text { C } 2018 \text { The Author(s). Published by S. Karger AG, Basel } \\
\text { www.karger.com/cpb }\end{array}$
\end{tabular}}

Sheng et al.: Baicalin Relieves Diabetic Cardiac Autonomic Neuropathy

glucose $\geq 7.8 \mathrm{mmol} / \mathrm{L}$ or random non-fasting blood glucose $\geq 11.1 \mathrm{mmol} / \mathrm{L}$ were considered to be type 2 diabetic rats [20-22]. Next, diabetic rats were randomly divided into three groups: the diabetic group (DM), the T2DM treated with baicalin group (DM+Bai), and the T2DM treated with normal saline group (DM+NS). Each group contained 10 rats. Diabetic rats continued to feed on the high-fat and high-sugar diet for 4 weeks, followed by injection of baicalin $(100 \mathrm{mg} / \mathrm{kg})$ intraperitoneally for 14 days. Baicalin was dissolved in normal saline and was purchased from Zelang Medical Technology Co., Nanjing, China. Baicalin quality was tallied with the monomer standard stipulated by the National Pharmacopoeia of China (FW = 446, purity N $98 \%$ by HPLC).

\section{Measurement of blood pressure and heart rate variability}

Blood pressure and heart rate were measured using the indirect tail-cuff method (Softron BP-98 A, Softron Co., Tokyo, Japan). Heart rate variability (HRV) was analyzed using the frequency domain of electrocardiogram recordings. The power of the RR-interval variations over the whole frequency range of the spectrum (total power frequency [TP], 0-0.5 Hz) and in the very-low frequency (VLF, 0.003-0.04 Hz), low frequency (LF, $0.04-0.15 \mathrm{~Hz}$ ) and high frequency (HF, $0.15-0.40 \mathrm{~Hz}$ ) ranges was calculated from shortterm 5-min recordings. LF indicates sympathetic activity, and HF indicates parasympathetic activity.

\section{Quantitative real-time PCR}

Total RNA was isolated from the SG using TRIzol Total RNA Reagent (Tiangen Biotech Co., Beijing, China). The reverse transcription reaction was completed using a RevertAid ${ }^{\mathrm{TM}}$ First Strand cDNA Synthesis Kit (Fermentas, Glen Burnie, MD) following the manufacturer's instructions. The primers were designed with Primer Express 3.0 software (Applied Biosystems, Foster City, CA), and the sequences were as follows: sense CACCCGCGAGTACAACCTTC and anti-sense CCCATACCCACCATCACACC for $\beta$-actin; sense CTTCGTTCCCTTCCACTTTG and anti-sense AGGGTGCTCTCCTTCACGTA for P2Y12; sense CCTATGTCTTGCCCGTGGAG and anti-sense CACACACTAGCAGGTCGTCA for interleukin-1 beta (IL-1 $\beta$ ); sense ATGGGCTCCCTCTCATCAGT and anti-sense GCTTGGTGGTTTGCTACGAC for tumor necrosis factor alpha (TNF- $\alpha$ ); and sense GGTGTCCTTGGTGTCTCTCG and anti-sense CTTCACGCGATCCTTAACGC for connexin (Cx43). Quantitative PCR was performed using SYBR® Green MasterMix in an ABI PRISM® 7500 Sequence Detection System (Applied Biosystems, Inc.). Individual experiments were carried out on each sample and repeated three times. All genes were normalized to the levels of endogenous $\beta$-actin. The relative expression of each tested gene was calculated by the $2^{-\Delta \Delta C t}$ method.

\section{Western blotting}

Total protein was extracted via homogenizing the SG sample by mechanical disruption in lysis buffer $(50 \mathrm{mmol} / \mathrm{L}$ Tris-Cl, pH 8.0, $150 \mathrm{mmol} / \mathrm{L} \mathrm{NaCl}, 0.1 \%$ sodium dodecyl sulfate [SDS], 1\% Nonidet P-40, $0.02 \%$ sodium deoxycholate, $100 \mu \mathrm{g} / \mathrm{mL}$ phenylmethylsulfonyl fluoride, $1 \mu \mathrm{g} / \mathrm{mL}$ aprotinin, $1 \%$ phosphatase inhibitors, and 1\% protease inhibitor), followed by incubation on ice for $40 \mathrm{~min}$. The lysates were centrifuged at $12,000 \times g$ for $15 \mathrm{~min}$ at $4^{\circ} \mathrm{C}$. The supernatants were collected for measurement of the protein concentrations using a bicinchoninic acid assay reagent kit and then stored at $-20^{\circ} \mathrm{C}$ until use. The supernatants were then diluted with sample buffer $(250 \mathrm{mmol} / \mathrm{L}$ Tris-Cl, $200 \mathrm{mmol} / \mathrm{L}$ dithiothreitol, $10 \%$ SDS, $0.5 \%$ bromophenol blue, and $50 \%$ glycerol) and denatured by heating at $95^{\circ} \mathrm{C}$ for $5 \mathrm{~min}$. Supernatant samples containing $20 \mu \mathrm{g}$ of protein were loaded onto 10\% SDS-polyacrylamide gels and transferred to polyvinylidene fluoride membranes. The membranes were then blocked for $1 \mathrm{~h}$ at room temperature in $5 \%$ nonfat dried milk in buffer containing $10 \mathrm{mM}$ Tris-HCl (pH 8.0), $150 \mathrm{mM} \mathrm{NaCl}$, and 0.05\% Tween-20. The membranes were nest incubated overnight at $4{ }^{\circ} \mathrm{C}$ with primary antibodies, including anti-rabbit P2Y12 (1:1000; ab184411, Abcam, Cambridge, UK), IL-1ß (1:500; AF5103, Affinity, Golden, CO), TNF- $\alpha$ (1:500; AF7014, Affinity), p38 mitogen-activated protein kinase (MAPK) (1:1000; 8690, Cell Signaling Technology, Danvers, MA), p-p38 MAPK (1:1000; 4511, Cell Signaling Technology), and anti-mouse Cx43 (1:1000; ab79010, Abcam). After three washes with 0.05\% Tween-20, the membranes were incubated with a horseradish peroxidase-conjugated goat anti-rabbit antibody (1:2000; Zhongshan Biotech Co., Beijing, China) or horseradish peroxidase-conjugated goat anti-mouse antibody (1:2000; Zhongshan Biotech Co.) for $1 \mathrm{~h}$ at room temperature. Protein signals were visualized and detected using the XRS+ chemiluminescence gel imaging system (Bio-Rad Co., Berkeley, CA). The membranes were stripped and incubated with mouse anti- $\beta$-actin (1:2000; A3854, Sigma-Aldrich, St. Louis, MO) to verify equal loading of samples. Changes in the integrated optical densities (IODs) of proteins were analyzed using Image Pro-Plus software.

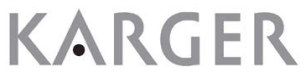




\section{Cellular Physiology Cell Physiol Biochem 2018;46:986-998 \begin{tabular}{l|l} 
and Biochemistry Published online: April 17, 2018 & $\begin{array}{l}\text { (c) } 2018 \text { The Author(s). Published by S. Karger AG, Basel } \\
\text { www.karger.com/cpb }\end{array}$
\end{tabular}}

\section{Double-label immunofluorescence}

Rats were euthanized and the SG were immediately dissected, washed in phosphate-buffered saline (PBS), and fixed in $4 \%$ paraformaldehyde for $24 \mathrm{~h}$ at $4{ }^{\circ} \mathrm{C}$. The specimen was then stored overnight in $20 \%$ sucrose in $4 \%$ paraformaldehyde. Tissues were sectioned at a thickness of $8 \mu \mathrm{m}$, and sections were stored at $-20^{\circ} \mathrm{C}$ until further processing. Co-expression of P2Y12 and glutamine synthetase (GS) was observed by double-label immunofluorescence. The sections were washed with PBS and permeabilized with $0.3 \%$ Triton $\mathrm{X}-100$ for $10 \mathrm{~min}$ at room temperature. Following a 30-min incubation with blocking solution, the sections were incubated with mouse anti-GS (1:150; ab64613, Abcam) and rabbit anti-P2Y12 (1:150; ab184411, Abcam) overnight at $4^{\circ} \mathrm{C}$. The sections were next rinsed and incubated with goat anti-rabbit TRITC (tetraethyl rhodamine isothiocyanate, 1:150; Zhongshan Biotech Co.) and goat anti-mouse FITC (1:150; Zhongshan Biotech Co.) for $1 \mathrm{~h}$ at $37^{\circ} \mathrm{C}$. The sections were then rinsed, mounted with an anti-fluorescent quenching agent, and imaged using a fluorescence microscope (TH4-200; Olympus, Japan).

\section{Enzyme-linked immunosorbent assay (ELISA) measurements}

Before decapitation, blood samples were collected from the orbit vein. After incubation at room temperature for $30 \mathrm{~min}$, samples were centrifuged at $3000 \mathrm{rpm}$ for $10 \mathrm{~min}$, and sera were collected and stored at $-20^{\circ} \mathrm{C}$. The serum epinephrine levels were quantified with an ELISA kit [23] according to the manufacturer's protocol (Senxiong Co., Shanghai, China). The reactions were read with an EnSpire Multilabel Reader (23001142, PerkinElmer, Waltham, MA) at $450 \mathrm{~nm}$. Epinephrine concentrations were determined based on a standard curve $[24,25]$.

\section{Molecular docking}

Molecular docking computations were performed with AutoDock 4.2 [26]. Molecular docking is a computer simulation tool that attempts to predict the binding mode of a ligand at the active site of a protein. Molecular docking studies mimic the natural interaction of a ligand with a protein. The docking approach is to position the ligand in different orientations and conformations within the binding site to calculate the optimal binding geometries and energies. Therefore, after performing the docking procedure, the proper conformation of the ligand at the active site of the protein is obtained and used to calculate molecular descriptors. For each ligand, a number of configurations, called poses, are generated and scored [26]. The score can be calculated as either the free energy of binding, which takes into account solvation and entropy (the enthalpic term of the free energy of binding) or a qualitative shaped-based numerical measure. The final top-scoring poses, along with their scores and conformation energies, are entered into a database for further analysis. The three-dimensional crystal structure of the agonist-bound human P2Y12 receptor was obtained from the Protein Data Bank (PDB ID: 4PY0) [27]. Baicalin (PubChem CID: 64982) was used as the ligand. Prior to the docking procedure, the protein and ligand structures were prepared with AutoDock Tools and Python scripts, named prepare_ligand4.py and prepare_receptor4.py, which are associated with the AutoDock 4.2 program. The binding pocket position in the target protein was specified with the AutoDock Tools molecular viewer. The parameters were kept at their default values. Finally, the output files were viewed using MGL tools and PyMol (http://www.pymol.org/).

\section{Statistical analysis}

Significant differences were evaluated using one-way analysis of variance followed by Dunnett's or Tukey's tests. Statistical analyses were performed using Graph Pad Prism version 5.0 (GraphPad Software, Inc, La Jolla, CA). The results are expressed as the mean \pm standard error. Differences were considered significant when $p<0.05$.

\section{Results}

Effects of baicalin on the serum concentration of epinephrine in T2DM rats

The ELISA results showed that the serum concentration of epinephrine was
Table 1. The concentration of epinephrine in the serum of rats (pg/ml). ${ }^{* *} p<0.01$ vs. Ctrl, ${ }^{\#} p<0.01$ vs. DM

\begin{tabular}{lllll}
\hline Group & Ctrl & DM & DM+Bai & DM+ NS \\
\hline Concentration & $26.2 \pm 2.2$ & $57.4 \pm 6.1^{* *}$ & $23.2 \pm 2.1^{\# \#}$ & $53.5 \pm 5.8^{* *}$
\end{tabular}


significantly higher in the T2DM group than in the Ctrl group $(\mathrm{n}=10, p<0.01)$. The serum epinephrine level was significantly lower in the T2DM group treated with baicalin than in the T2DM group without baicalin treatment $(\mathrm{n}=$ $10, p<0.01$ ). There were no significant differences between the DM+NS and DM groups or between the Ctrl and DM+Bai groups (n $=10, p>0.05$; Table 1).

Effects of baicalin on blood pressure and heart rate in T2DM rats The systolic blood pressure, diastolic blood pressure, mean arterial pressure, and heart rate were increased in the T2DM group compared with those in the Ctrl group ( $\mathrm{n}=10, p<$
Table 2. Changes of blood pressure and heart rate in rats. $* * p<0.01 \mathrm{vs.}$ Ctrl, ${ }^{\#} p<0.01$ vs. DM

\begin{tabular}{lcccc}
\hline Group & \multicolumn{3}{c}{ Blood pressure } & Heart rate \\
\hline & SBP (mmHg) & DBP (mmHg) & MBP (mmHg) & (beat/min) \\
Ctrl & $104.67 \pm 12.2$ & $79.7 \pm 9.8$ & $88.04 \pm 10.1$ & $314.9 \pm 10.35$ \\
DM & $131.67 \pm 14.51^{* *}$ & $87.5 \pm 13.55^{* *}$ & $97.43 \pm 11.27^{* *}$ & $360.8 \pm 43.4^{* *}$ \\
DM+Bai & $113.68 \pm 12.84^{\# \#}$ & $70.21 \pm 7.76^{\# \#}$ & $85.47 \pm 9.33^{\# \#}$ & $313.31 \pm 19.07^{\# \#}$ \\
DM+NS & $128.93 \pm 13.2^{* *}$ & $86.1 \pm 10.42^{* *}$ & $95.31 \pm 10.42^{* *}$ & $358.7 \pm 20.2^{* *}$ \\
\hline
\end{tabular}

Table 3. Changes of heart rate variability in rats. ${ }^{* *} p<0.01$ vs. Ctrl, ${ }^{\#} p$ $<0.01$ vs. DM

\begin{tabular}{llllll}
\hline & TP $\left(\mathrm{ms}^{2}\right)$ & $\mathrm{VLF}\left(\mathrm{ms}^{2}\right)$ & $\mathrm{LF}\left(\mathrm{ms}^{2}\right)$ & $\mathrm{HF}\left(\mathrm{ms}^{2}\right)$ & $\mathrm{LF} / \mathrm{HF}$ \\
\hline Ctrl & $138.16 \pm 4.34$ & $118.8 \pm 5.16$ & $7.22 \pm 1.98$ & $12.28 \pm 2.10$ & $0.6 \pm 0.25$ \\
DM & $109.17 \pm 1.91^{* *}$ & $105.6 \pm 2.28^{* *}$ & $2.38 \pm 1.27^{* *}$ & $0.91 \pm 0.32^{* *}$ & $2.48 \pm 0.48^{* *}$ \\
DM+Bai & $134.28 \pm 6.54^{\# \#}$ & $121.6 \pm 4.82^{\# \#}$ & $4.37 \pm 0.27^{\# \#}$ & $9.24 \pm 0.798^{\# \#}$ & $0.62 \pm 0.32^{\# \#}$ \\
DM+NS & $111.04 \pm 1.32^{* *}$ & $107.3 \pm 3.13^{* *}$ & $3.14 \pm 1.42^{* *}$ & $1.21 \pm 0.52^{* *}$ & $2.59 \pm 0.63^{* *}$ \\
\hline
\end{tabular}

0.01). Compared with the T2DM group, the systolic blood pressure, diastolic blood pressure, mean arterial pressure, and heart rate were decreased in the T2DM group treated with baicalin $(\mathrm{n}=10, p<0.01)$. There were no significant differences between the $\mathrm{DM}+\mathrm{NS}$ and DM groups or between the Ctrl and DM+Bai groups ( $\mathrm{n}=10, p>0.05$, Table 2). The elevated blood pressure and increased heart rate suggested increased excitability of the cardiac sympathetic nerve.

\section{Effects of baicalin on HRV in T2DM rats}

Frequency-domain analysis demonstrated that the TP, VLF, LF, and HF were decreased in the T2DM group compared with those in the Ctrl group, suggesting that both sympathetic and parasympathetic tones were reduced in T2DM ( $\mathrm{n}=10, p<0.01)$. Compared with the control group, the LF/HF ratio was significantly increased in T2DM. TP, VLF, LF, and HF were increased in T2DM rats treated with baicalin compared with untreated T2DM rats $(\mathrm{n}=10$, $p<0.01$ ). The LF/HF ratio in diabetic rats was decreased following baicalin treatment $(\mathrm{n}=$ $10, p<0.01$ ). There were no significant differences between the DM+NS and DM groups or between the Ctrl and DM+Bai groups ( $\mathrm{n}=10, p>0.05$; Table 3$)$.

\section{Effects of baicalin on the expression of P2Y12 in the SG}

The real-time PCR results showed that the transcript level of P2Y12 mRNA was significantly higher in the T2DM group than in the control group ( $\mathrm{n}=10, p<0.01$; Fig. 1A). However, the elevated P2Y12 mRNA levels in the T2DM group were significantly relieved after treatment with baicalin $(\mathrm{n}=10, p<0.01$; Fig. $1 \mathrm{~A})$. There was no significant difference between the DM and DM+NS groups or between the Ctrl and DM+Bai groups ( $\mathrm{n}=10, p>$ 0.05; Fig. 1A).

The protein expression level of P2Y12 was further analyzed by western blotting (Fig. 1B). Using image analysis, the stain values (IOD) of the P2Y12 protein mass (normalized to the individual $\beta$-actin internal control) in the T2DM group were observed to be 5.1 -fold higher than those in the control group ( $\mathrm{n}=10, p<0.01$, Fig. $1 \mathrm{C})$. In addition, the IOD of P2Y12 
in the T2DM group treated with baicalin was decreased by $63 \%$ compared with the values observed in the T2DM group without treatment ( $\mathrm{n}=10, p<0.01$; Fig. 1C). There was no significant difference between the $\mathrm{DM}$ and $\mathrm{DM}+\mathrm{NS}$ groups or between the Ctrl and $\mathrm{DM}+\mathrm{Bai}$ groups $(\mathrm{n}=10, p>0.05$; Fig. 1C).

Double-label immunofluorescence of P2Y12 and GS in the SG

GS is a marker of SGCs. And its upregulation in the $S G$ suggests activation of SGCs after a nervous injury stimulus [28]. Co-expression of the P2Y12 receptor and GS is shown in Fig. 2. P2Y12 and GS were colocalized in the SGCs of the SG, indicating that the P2Y12 receptor was expressed in these SGCs. Co-expression of the P2Y12 receptor and GS was higher in the T2DM group than in the control group. However, co-expression of P2Y12 and GS was lower in the T2DM group treated with baicalin than in the T2DM group. There was no significant difference between the DM and DM+NS groups.

\section{Effects of baicalin on $I L-1 \beta$ and TNF- $\alpha$} expression in the $S G$

Activated stellate glia cells release several inflammatory factors. Our realtime PCR results demonstrated that the expression levels of IL- $1 \beta$ and TNF- $\alpha$ mRNA were significantly higher in the T2DM group than in the control group $(\mathrm{n}=10, p$ $<0.01$; Fig. 3A). However, the elevated IL$1 \beta$ and TNF- $\alpha$ mRNA levels in the T2DM group were significantly relieved following treatment with baicalin $(\mathrm{n}=10, p<0.01$, Fig. 3A). There was no significant difference between the DM and DM+NS groups or between the Ctrl and DM+Bai groups ( $\mathrm{n}=$ $10, p>0.05$; Fig. 3A).

The protein expression levels of IL- $1 \beta$ and TNF- $\alpha$ were further determined by western blotting (Fig. 3B). Using image analysis, the stain values (IOD) of the IL-1 $\beta$ and TNF- $\alpha$ protein masses (normalized to the individual $\beta$-actin internal control) were significantly higher in the T2DM group than in the control group $(\mathrm{n}=10, p<0.01$; Fig. 3$)$. In addition, the protein mass values of IL-1 $\beta$ and TNF- $\alpha$ were lower in the T2DM group treated with baicalin than in the untreated T2DM group $(\mathrm{n}=10, p<0.01$; Fig. 3$)$. There was no significant difference between the DM and DM+NS groups or between the Ctrl and DM+Bai groups ( $\mathrm{n}=10, p>$ 0.05; Fig. 3).

\section{Effects of baicalin on the expression of $C x 43$ in the $S G$}

$\mathrm{Cx} 43$, the most important and common gap junction protein isoform in the body, is associated with nerve damage [29]. Our real-time PCR results showed that expression of Cx43 
mRNA in T2DM rats was increased 4.6-fold compared with control rats $(\mathrm{n}=10$, $p<0.01$; Fig. 4A). Baicalin treatment significantly decreased the expression of Cx43 mRNA in T2DM rats ( $\mathrm{n}=10, p<0.01$; Fig. 4A). There was no significant difference between the DM and DM+NS groups or between the Ctrl and DM+Bai groups ( $\mathrm{n}=10, p>0.05$; Fig. $4 A)$.

Cx43 protein expression was detected by western blotting (Fig. 4B). The image analysis results indicate that the IOD ratio of Cx43 to $\beta$-actin in T2DM rats was increased 2.16-fold compared with control rats ( $\mathrm{n}=10, p<0.01$; Fig. 4C). Compared with the T2DM group, the IOD ratio of $\mathrm{Cx} 43$ to $\beta$-actin was decreased by $86 \%$ in T2DM rats treated with baicalin $(\mathrm{n}=10, p<$ 0.01 ; Fig. 4C). There was no significant difference between the DM and DM+NS groups or between the Ctrl and DM+Bai groups $(\mathrm{n}=10$, $p>0.05$; Fig. 4C).

Effects of baicalin on p38 MAPK and p-p38 $M A P K$ expression in the $S G$

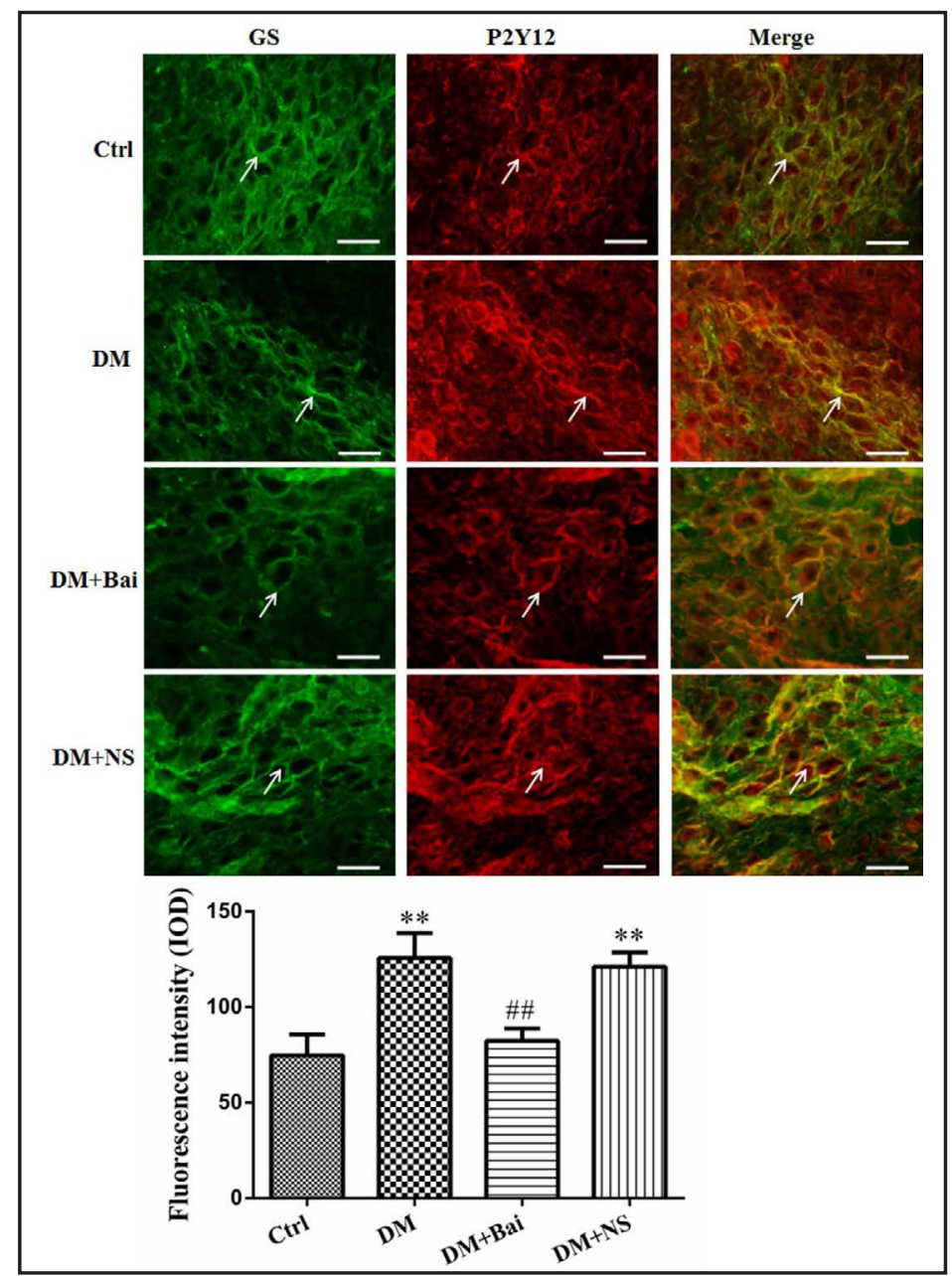

Fig. 2. Double-label immunofluorescence of P2Y12 and GS in the SG. Co-expression was observed of the P2Y12 receptor and GS in the SG. The green signal represents GS staining with FITC, and the red signal indicates P2Y12 staining with TRITC. The merge represents the P2Y12 and GS double staining image. Scale bar, $50 \mu \mathrm{m}$. The bar graphs show the statistical results for co-expression of P2Y12 and GS in the SG. ** $\mathrm{p}<0.01$ vs. Ctrl, ${ }^{\# \#} \mathrm{p}<0.01$ vs. DM. ( $\mathrm{n}=10$ in each group).

The expression levels of p38 MAPK and p-p38 MAPK were detected by western blotting. The IOD ratio of p38 MAPK to $\beta$-actin was not significantly different among the four groups $\left(\mathrm{F}_{(3,8)}=1.732, p=0.24\right.$, data not shown $)$. However, the IOD ratio of p-p38 MAPK to p38 MAPK was 3.1-fold higher in the DM group than in the control group ( $\mathrm{n}=10, p<0.01$ ).

Compared with the T2DM group, the IOD ratio of p-p38 MAPK to p38 MAPK was decreased by $73 \%$ in T2DM rats treated with baicalin ( $n=10, p<0.01$; Fig. 5). There was no significant difference between the DM and DM+NS groups or between the Ctrl and DM+Bai groups ( $\mathrm{n}=10, p>0.05$; Fig. 5 ).

\section{Molecular docking of baicalin on P2Y12 protein}

Molecular docking of baicalin on the P2Y12 receptor was analyzed using AutoDock 4.2. The docking score of baicalin on the P2Y12 receptor (kcal/mol) showed that baicalin was a perfect fit for interacting with the P2Y12 receptor (Table 4). The perfect match enabled 
Fig. 3. Effects of baicalin on mRNA and protein expression of IL-1 $\beta$ and TNF- $\alpha$ in the SG of T2DM rats. (A, D) Expression of IL-1 $\beta$ (A) and TNF- $\alpha$ (D) mRNA was detected by real-time PCR analysis using $\beta$-actin as an internal control. The results are expressed as the mean \pm standard error of fold changes from three independent experiments. (B, E) The protein levels of IL-1 $\beta$ (B) and TNF- $\alpha$ (E) were measured by western blotting. The bar histograms show the IOD ratios of the IL-1 $\beta$ (C) and TNF- $\alpha$ (F) protein levels to those of $\beta$-actin in each group, and the values are the mean \pm standard error from three independent experiments. ${ }^{* *} \mathrm{p}<0.01$ vs. Ctrl, \#\# $\mathrm{p}<0.01$ vs. DM.

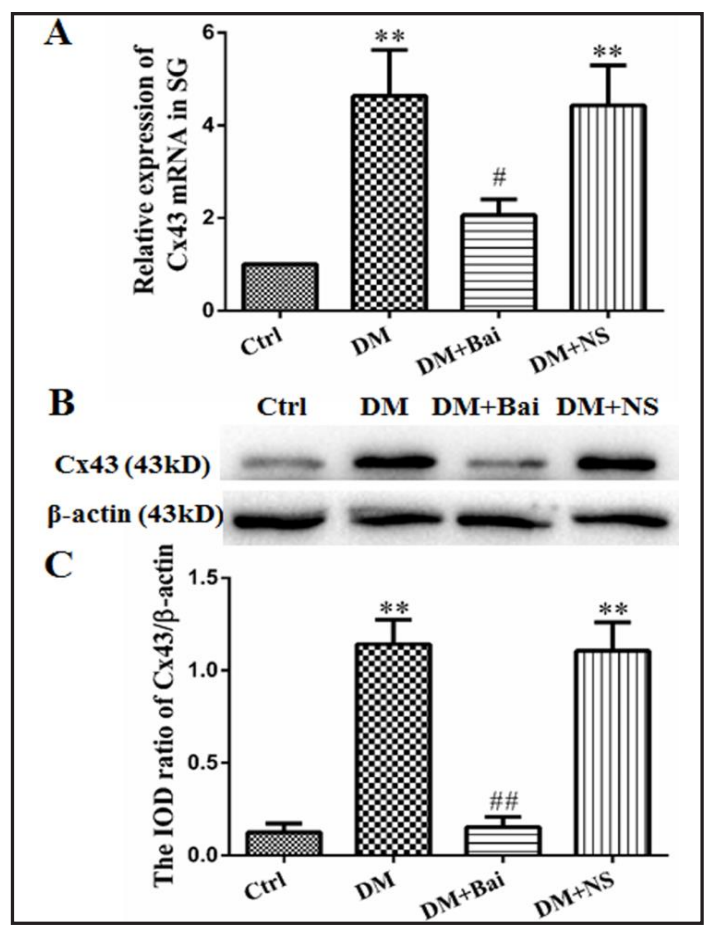

Fig. 4. Effects of baicalin on the expression of $\mathrm{Cx} 43$ mRNA and protein in the SG of T2DM rats. (A) Expression of $\mathrm{Cx} 43$ mRNA was examined by real-time PCR. (B) The protein level of $\mathrm{Cx} 43$ was measured by western blotting. (C) The bar histograms show the IOD ratio of $\mathrm{Cx} 43$ to $\beta$-actin in each group, and the values are the mean \pm standard error from three independent experiments. ${ }^{* *} \mathrm{p}<0.01$ vs. Ctrl, \#\# $\mathrm{p}<0.01$ vs. DM.
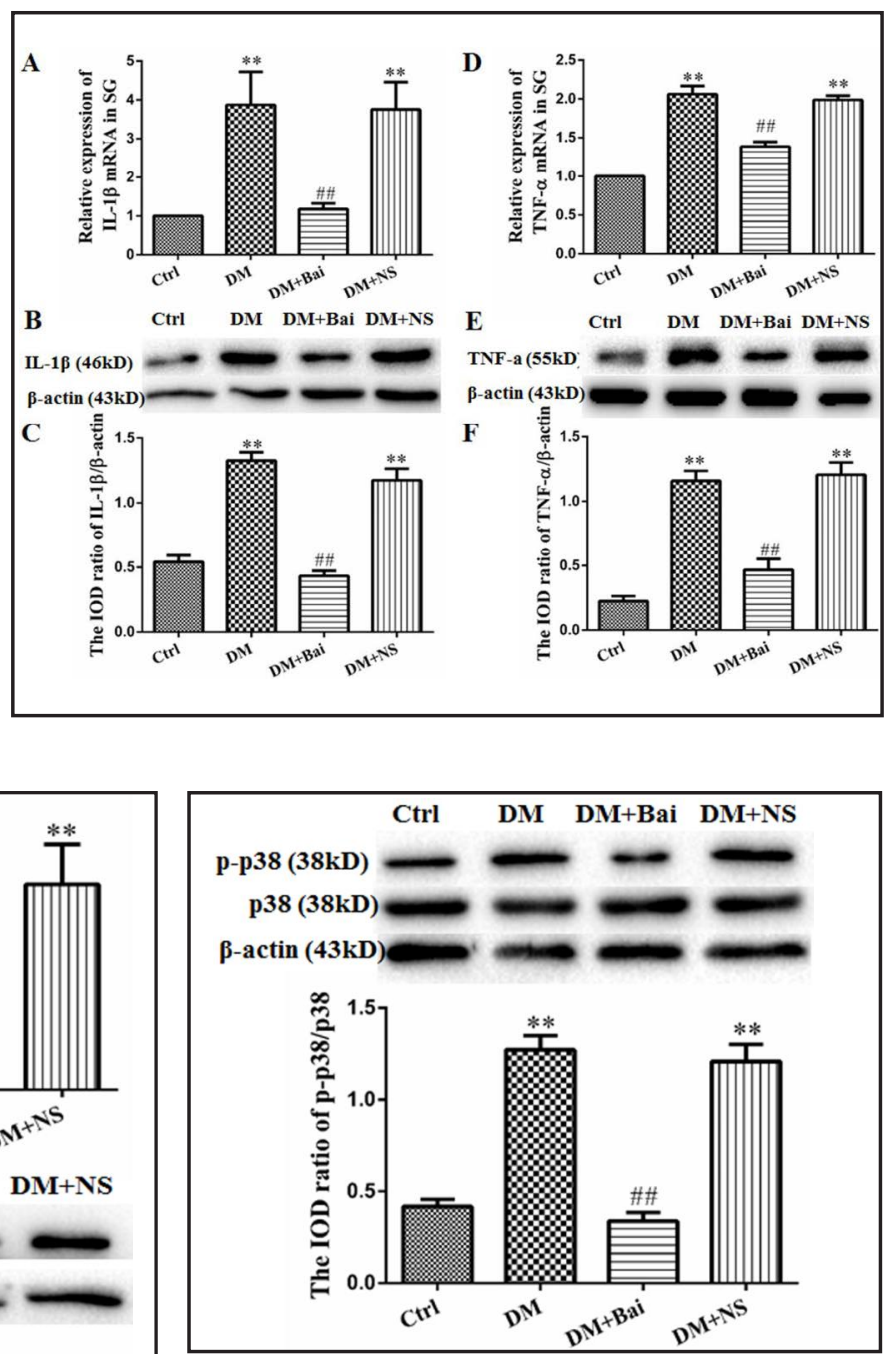

Fig. 5. Effects of baicalin on the expression levels of p38 MAPK and p-p38 MAPK in the SG of T2DM rats. The expression levels of p38 MAPK and p-p38 MAPK were detected by western blotting. The IOD ratio of p38 MAPK to $\beta$-actin was not significantly different among the four groups $\left(\mathrm{F}_{(3,8)}=1.73, \mathrm{p}=0.24\right)$. The IOD ratio of p-p38 MAPK to p38 MAPK was higher in the T2DM group than in the control group $(n=10$, $\mathrm{p}<0.01$ ). The IOD ratio of $\mathrm{p}-\mathrm{p} 38$ MAPK to p38 MAPK in T2DM rats treated with baicalin was markedly decreased compared with the T2DM group $(n=10$, $\mathrm{p}<0.01$ ). The values are the mean \pm standard error from three independent experiments. ${ }^{* *} \mathrm{p}<0.01$ vs. Ctrl, ${ }^{\# \#}$ p $<0.01$ vs. DM.

baicalin to interact with residues both deep in the 2-mesADP-binding pocket as well as in the outer sphere (Fig. 6).

\section{KARGER}


Fig. 6. Molecular docking of baicalin on the P2Y12 protein. Modeling of baicalin docking to the P2Y12 protein was simulated with AutoDock 4.2 software. (A) Structural model of the binding site of human P2Y12 for baicalin (upper, forward view; lower, top view). (B) Docking pocket of human P2Y12. (C) Molecular docking analysis of the interaction between human P2Y12 and baicalin. Molecular docking poses of baicalin are shown in blue within the active site of human P2Y12 (PDB ID: 4PY0). The yellow dashed line is a hydrogen bond between the connected residues (Lys 286, Asn 197, His 192, Arg 171, and Gln 104) and baicalin. The results indicates that baicalin interactes with hP2Y12 protein.

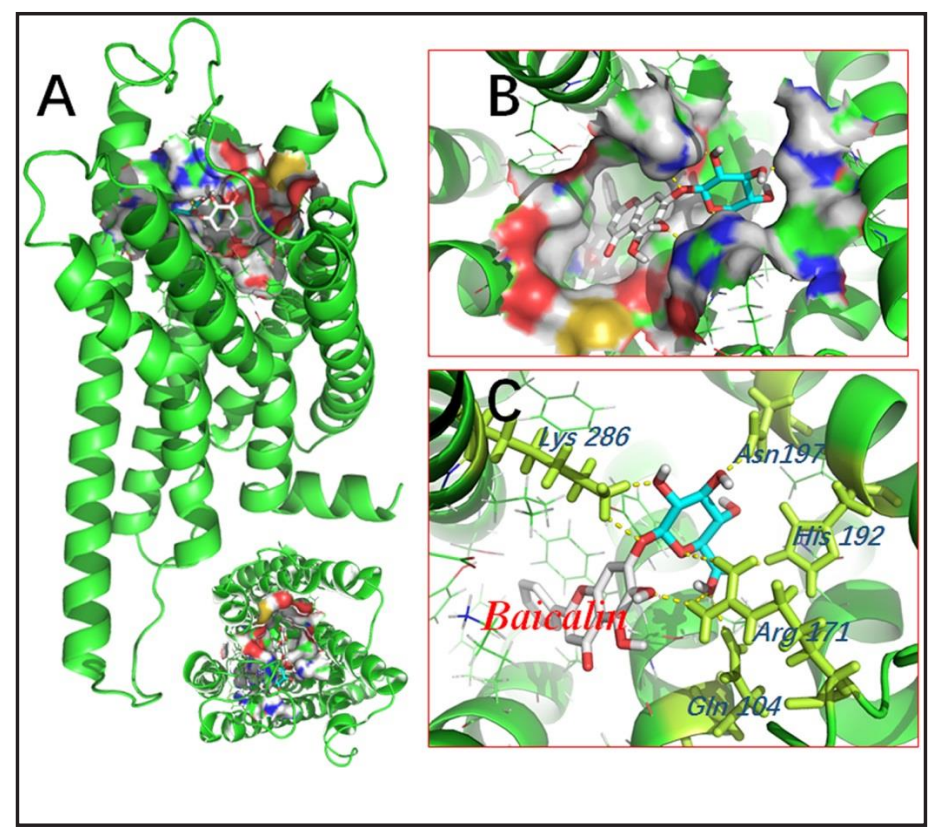

\section{Discussion}

Diabetes frequently results in an imbalance in the autonomic nervous system linked to the cardiovascular system. This imbalance is usually measured by HRV [30-32]. HRV can comprehensively, quantitatively, and intuitively reflect at an early stage the functional status of cardiovascular, sympathetic, and vagus nerves in diabetic patients [33]. Our experiments indicated that the TP, VLF, $\mathrm{LF}$, and HF values in diabetic rats were decreased but that the LF/HF ratio was increased, suggesting that the autonomic nervous system was damaged in diabetic rats and that the sympathetic nerve was relatively excited. HRV reflects the sympathetic activity of the autonomic nervous system and the balanced coordination between the sympathetic and vagus nerves. Our data also indicate signs of excited sympathetic nerves, such as elevated blood pressure, increased heart rate, and high levels of serum epinephrine. HRV is the most accurate and sensitive index to judge whether diabetic patients have autonomic neuropathy [32]. Our results showed that diabetic rats had autonomic neuropathy. Furthermore, we demonstrated that baicalin increased the depressed HRV and alleviated the sympathetic activity.
Table 4. MOE score of the P2Y12 protein and baicalin ( $\mathrm{kcal} / \mathrm{mol})$. The predicted binding affinity is in $\mathrm{kcal} /$ mol (energy). The RMSD values were calculated as related to the best mode and only used movable heavy atoms. Two variants of the RMSD metrics are provided: RMSD lb (RMSD lower bound) and RMSD ub (RMSD upper bound), which is how the atoms are matched in the distance calculation

\begin{tabular}{cccc}
\hline Mode & $\begin{array}{c}\text { Affinity } \\
\text { (kcal/mol) }\end{array}$ & Rist from & Best mode \\
\hline 1 & -9.3 & 0.000 & 0.000 \\
2 & -8.4 & 3.45 & 7.14 \\
3 & -8.3 & 3.396 & 7.219 \\
4 & -8.2 & 4.353 & 8.495 \\
5 & -8.0 & 3.572 & 7.3 \\
6 & -7.5 & 3.757 & 8.106 \\
7 & -7.2 & 1.483 & 2.651 \\
\hline 8 & -7.1 & 3.645 & 5.549 \\
9 & -7.0 & 4.868 & 8.51 \\
\hline
\end{tabular}




\section{Cellular Physiology Cell Physiol Biochem 2018;46:986-998 \begin{tabular}{l|l|l} 
and Biochemistry 10.1159/000488828 & $\begin{array}{l}\text { C } 2018 \text { The Author(s). Published by S. Karger AG, Basel } \\
\text { www.karger.com/cpb }\end{array}$
\end{tabular}}

Sheng et al.: Baicalin Relieves Diabetic Cardiac Autonomic Neuropathy

T2DM is currently considered to be a chronic inflammatory response. The P2Y12 receptor has been observed to be involved in diabetes and expressed in human $\beta$ cells and brown adipocytes, the rodent pancreas and islet and cell preparations, and $\beta$-cell lines [8]. Patients with T2DM have an upregulated P2Y12 signaling pathway [34]. Our results showed that the mRNA and protein expression levels of P2Y12 were increased in the SG of diabetic rats. SGCs, the primary type of glial cells in most types of peripheral ganglia, have functions similar to those of astrocytes in the central nervous system. For example, they release proinflammatory cytokines, such as IL-1 $\beta$, interleukin-6 (IL-6), and monocyte chemoattractant protein-1 (MCP-1), and mediate the inflammatory response [5, 35]. The P2Y12 receptor was expressed in the SGCs of the SG [5]. Tested by double-label immunofluorescence, P2Y12 and GS (a marker of SGCs) were colocalized in the SGCs of the SG. P2Y12 receptor activation in human microglia results in increased release of TNF- $\alpha$ and IL-6 [36], whereas P2Y12 inhibitors reduce the levels of TNF- $\alpha$ and C-reactive protein (CRP) [37]. The elevated GS in the SG in our study suggested that SGCs were activated by the nerve injury stimulation induced by T2DM.

Elevated P2Y12 expression promoted the release of TNF- $\alpha$ and IL-1 $\beta$ by activated SGCs and a stronger inflammatory response. These proinflammatory cytokines aggravate the neuronal damage and cause greater ATP release from injured neurons, consequently generating more breakdown products, such as ADP, and activating the P2Y12 receptor in the SGCs [9]. Our results also indicated that baicalin treatment significantly decreased the upregulation of P2Y12 mRNA and protein in T2DM rats. Molecular docking between baicalin and the P2Y12 protein predicted that baicalin interacted with the P2Y12 receptor, and the binding interaction was further stabilized by multiple hydrogen bonds. Higher negative interaction energy indicates a more stable interaction between the P2Y12 receptor and baicalin. Thus, baicalin binding to the P2Y12 receptor inhibited P2Y12 expression and activation. Furthermore, baicalin may decrease up-regulated sympathoexcitatory activity by inhibiting the P2Y12 receptor in the SG SGCs to maintain the balance between sympathetic and parasympathetic nerves in DCAN rats.

Connexins, the primary gap junction-forming proteins, play a crucial role as subunits of gap junction channels, permitting rapid transport of ions or low molecular-mass metabolites $(<1000 \mathrm{Da})$ and secondary messenger molecules between adjoining cells [38]. Cx43 is a major gap junction protein in SGCs [39]. Our results showed that the mRNA and protein expression levels of $\mathrm{Cx} 43$ were markedly upregulated in diabetic rats. When neurons are injured, ATP, as a signaling molecule, is released from neurons. ATP and its breakdown products bind to purinergic receptors located on both neurons and glia, providing positive feedback. Gap junctions are strengthened between SGCs, between neurons and glia, and between neurons. Subsequently, neurons and SGCs become hyper-responsive to purinergic stimulation [39]. Baicalin treatment significantly decreased the expression levels of Cx43 mRNA and protein in T2DM rats. These results suggest that baicalin, through its interaction with the P2Y12 receptor and by decreasing its expression and activation, abolished the positive feedback between neuron damage and glia activation, as well as decreased the upregulated expression levels of Cx43 mRNA and protein in the SG of diabetic rats, which in turn reduced SGC activation.

p38 MAPK participates in the sympathoexcitatory response induced by central inflammation via intracerebroventricular injection of lipopolysaccharide [40] or by intracerebroventricular administration of the chemokine stromal cell-derived factor-1 (SDF-1/CXCL12) [41] and is positively associated with sympathetic nerve activity induced by endoplasmic reticulum stress in rats with heart failure [42]. Our experimental data confirmed that the phosphorylation of p38 MAPK in the SG was elevated in diabetic rats. Compared with diabetic rats, p-p38 MAPK in the SG was markedly decreased in baicalintreated diabetic rats. p38 MAPK inhibitors attenuate SDF-1-induced excitatory responses and reduced the sympathoexcitatory response to lipopolysaccharide [40, 41]. The p38 MAPK pathway is involved in P2Y12 receptor-mediated pathological changes [43]. Our results 
Sheng et al.: Baicalin Relieves Diabetic Cardiac Autonomic Neuropathy

revealed that the inhibitory effects of baicalin on the upregulation of the P2Y12 receptor in the SG of DM rats might be related to intracellular p38 MAPK signaling.

\section{Conclusion}

Upregulation of the P2Y12 receptor in the SG of type 2 diabetic rats is related to DCAN pathological changes. Baicalin treatment decreases the elevated expression and activation of the P2Y12 receptor and reduces the phosphorylation of p38 MAPK in the SG of diabetic rats, resulting in an amelioration of DCAN.

\section{Disclosure Statement}

The authors declare that there are no conflicts of interest.

\section{Acknowledgements}

This study was supported by grants from the National Natural Science Foundation of China (81560219, 81360436, 31560276, 81570735 and 81200853), a grant from the young scientist training object of Jiangxi Province (20153BCB23030), a grant from the Natural Science Foundation of Jiangxi Province (20171BAB205025) and a grant from the Innovation Foundation of the Graduate School of Nanchang University (cx2016358).

\section{References}

1 Ogurtsova K, da Rocha Fernandes JD, Huang Y, Linnenkamp U, Guariguata L, Cho NH, Cavan D, Shaw JE, Makaroff LE: Idf diabetes atlas: Global estimates for the prevalence of diabetes for 2015 and 2040 Diabetes Res Clin Pract 2017;128:40-50.

2 Pop-Busui R: Cardiac autonomic neuropathy in diabetes: A clinical perspective. Diabetes Care 2010;33:434441.

3 Spallone V, Ziegler D, Freeman R, Bernardi L, Frontoni S, Pop-Busui R, Stevens M, Kempler P, Hilsted J, Tesfaye S, Low P, Valensi P, Toronto Consensus Panel on Diabetic N: Cardiovascular autonomic neuropathy in diabetes: Clinical impact, assessment, diagnosis, and management. Diabetes Metab Res Rev 2011;27:639-653.

4 Pather N, Partab P, Singh B, Satyapal KS: The sympathetic contributions to the cardiac plexus. Surg Radiol Anat 2003;25:210-215.

5 Hanani M: Satellite glial cells in sympathetic and parasympathetic ganglia: In search of function. Brain Res Rev 2010;64:304-327.

-6 Hanani M: Intercellular communication in sensory ganglia by purinergic receptors and gap junctions: Implications for chronic pain. Brain Res 2012;1487:183-191.

7 Warwick RA, Hanani M: The contribution of satellite glial cells to chemotherapy-induced neuropathic pain. Eur J Pain 2013;17:571-580.

-8 Burnstock G, Novak I: Purinergic signalling and diabetes. Purinergic Signal 2013;9:307-324.

9 Del Puerto A, Wandosell F, Garrido JJ: Neuronal and glial purinergic receptors functions in neuron development and brain disease. Front Cell Neurosci 2013;7:197.

10 Burnstock G: Purinergic signaling in the cardiovascular system. Circ Res 2017;120:207-228.

11 Sipe GO, Lowery RL, Tremblay ME, Kelly EA, Lamantia CE, Majewska AK: Microglial p2y12 is necessary for synaptic plasticity in mouse visual cortex. Nat Commun 2016;7:10905.

12 Tamagawa T, Shinoda M, Honda K, Furukawa A, Kaji K, Nagashima H, Akasaka R, Chen J, Sessle BJ, Yonehara Y, Iwata K: Involvement of microglial p2y12 signaling in tongue cancer pain. J Dent Res 2016;95:11761182. 


\section{Cellular Physiology Cell Physiol Biochem 2018;46:986-998 \begin{tabular}{l|l|l} 
and Biochemistry & $\begin{array}{l}\text { DOI: 10.1159/000488828 } \\
\text { Published } 2018\end{array}$ & $\begin{array}{l}\text { @ } 2018 \text { The Author(s). Published by S. Karger AG, Basel } \\
\text { www.karger.com/cpb }\end{array}$
\end{tabular}}

Sheng et al.: Baicalin Relieves Diabetic Cardiac Autonomic Neuropathy

13 Horvath G, Goloncser F, Csolle C, Kiraly K, Ando RD, Baranyi M, Kovanyi B, Mate Z, Hoffmann K, Algaier I, Baqi Y, Muller CE, Von Kugelgen I, Sperlagh B: Central p2y12 receptor blockade alleviates inflammatory and neuropathic pain and cytokine production in rodents. Neurobiol Dis 2014;70:162-178.

$>14$ Yao J, Cao X, Zhang R, Li YX, Xu ZL, Zhang DG, Wang LS, Wang JY: Protective effect of baicalin against experimental colitis via suppression of oxidant stress and apoptosis. Pharmacogn Mag 2016;12:225-234.

15 Yang W, Li H, Cong X, Wang X, Jiang Z, Zhang Q, Qi X, Gao S, Cao R, Tian W: Baicalin attenuates lipopolysaccharide induced inflammation and apoptosis of cow mammary epithelial cells by regulating nfkappab and hsp72. Int Immunopharmacol 2016;40:139-145.

-16 Dinda B, Dinda S, DasSharma S, Banik R, Chakraborty A, Dinda M: Therapeutic potentials of baicalin and its aglycone, baicalein against inflammatory disorders. Eur J Med Chem 2017;131:68-80.

17 Fang P, Yu M, Zhang L, Wan D, Shi M, Zhu Y, Bo P, Zhang Z: Baicalin against obesity and insulin resistance through activation of akt/as160/glut4 pathway. Mol Cell Endocrinol 2017;448:77-86.

18 Ma P, Mao XY, Li XL, Ma Y, Qiao YD, Liu ZQ, Zhou HH, Cao YG: Baicalin alleviates diabetesassociated cognitive deficits via modulation of mitogen-activated protein kinase signaling, brainderived neurotrophic factor and apoptosis. Mol Med Rep 2015;12:6377-6383.

19 Xi YL, Li HX, Chen C, Liu YQ, Lv HM, Dong SQ Luo EF, Gu MB, Liu H: Baicalin attenuates high fat diet-induced insulin resistance and ectopic fat storage in skeletal muscle, through modulating the protein kinase b/ glycogen synthase kinase 3 beta pathway. Chin J Nat Med 2016;14:48-55.

20 Li G, Xu H, Zhu S, Xu W, Qin S, Liu S, Tu G, Peng H, Qiu S, Yu S, Zhu Q Fan B, Zheng C, Liang S: Effects of neferine on ccl5 and ccr5 expression in scg of type 2 diabetic rats. Brain Res Bull 2013;90:79-87.

-21 Romanovsky D, Walker JC, Dobretsov M: Pressure pain precedes development of type 2 disease in zucker rat model of diabetes. Neurosci Lett 2008;445:220-223.

-22 Hulsegge G, Spijkerman AM, van der Schouw YT, Bakker SJ, Gansevoort RT, Smit HA, Verschuren WM: Trajectories of metabolic risk factors and biochemical markers prior to the onset of cardiovascular disease - the doetinchem cohort study. PLoS One 2016;11:e0155978.

23 Tu G, Zou L, Liu S, Wu B, Lv Q Wang S, Xue Y, Zhang C, Yi Z, Zhang X, Li G, Liang S: Long noncoding nonratt021972 sirna normalized abnormal sympathetic activity mediated by the upregulation of $\mathrm{p} 2 \mathrm{x} 7$ receptor in superior cervical ganglia after myocardial ischemia. Purinergic Signal 2016;12:521-535.

24 Liu J, Li G, Peng H, Tu G, Kong F, Liu S, Gao Y, Xu H, Qiu S, Fan B, Zhu Q, Yu S, Zheng C, Wu B, Peng L, Song M, Wu Q, Liang S: Sensory-sympathetic coupling in superior cervical ganglia after myocardial ischemic injury facilitates sympathoexcitatory action via p2x7 receptor. Purinergic Signal 2013;9:463-479.

25 Li G, Liu S, Yang Y, Xie J, Liu J, Kong F, Tu G, Wu R, Liang S: Effects of oxymatrine on sympathoexcitatory reflex induced by myocardial ischemic signaling mediated by $\mathrm{p} 2 \mathrm{x}(3)$ receptors in rat scg and drg. Brain Res Bull 2011;84:419-424.

-26 Trott 0, Olson AJ: Autodock vina: Improving the speed and accuracy of docking with a new scoring function, efficient optimization, and multithreading. J Comput Chem 2010;31:455-461.

27 Zhang J, Zhang K, Gao ZG, Paoletta S, Zhang D, Han GW, Li T, Ma L, Zhang W, Muller CE, Yang H, Jiang H, Cherezov V, Katritch V, Jacobson KA, Stevens RC, Wu B, Zhao Q: Agonist-bound structure of the human p2y12 receptor. Nature 2014;509:119-122.

-28 Miller KE, Richards BA, Kriebel RM: Glutamine-, glutamine synthetase-, glutamate dehydrogenase- and pyruvate carboxylase-immunoreactivities in the rat dorsal root ganglion and peripheral nerve. Brain Res 2002;945:202-211.

29 Lurtz MM, Louis CF: Purinergic receptor-mediated regulation of lens connexin43. Invest Ophthalmol Vis Sci 2007;48:4177-4186.

-30 Balcioglu AS, Muderrisoglu H: Diabetes and cardiac autonomic neuropathy: Clinical manifestations, cardiovascular consequences, diagnosis and treatment. World J Diabetes 2015;6:80-91.

-31 Carricarte Naranjo C, Sanchez-Rodriguez LM, Brown Martinez M, Estevez Baez M, Machado Garcia A: Permutation entropy analysis of heart rate variability for the assessment of cardiovascular autonomic neuropathy in type 1 diabetes mellitus. Comput Biol Med 2017;86:90-97.

-32 Stables CL, Glasser RL, Feldman EL: Diabetic cardiac autonomic neuropathy: Insights from animal models. Auton Neurosci 2013;177:74-80.

-33 Karayannis G, Giamouzis G, Cokkinos DV, Skoularigis J, Triposkiadis F: Diabetic cardiovascular autonomic neuropathy: Clinical implications. Expert Rev Cardiovasc Ther 2012;10:747-765. 


\section{Cellular Physiology Cell Physiol Biochem 2018;46:986-998 \begin{tabular}{l|l} 
DOI: 10.1159/000488828 \\
and Biochemistry
\end{tabular} $\begin{aligned} & \text { O } 2018 \text { The Author(s). Published by S. Karger AG, Basel } \\
& \text { www.karger.com/cpb }\end{aligned}$

-34 Suryadevara S, Ueno M, Tello-Montoliu A, Ferreiro JL, Desai B, Rollini F, Box LC, Zenni M, Guzman LA, Bass TA, Angiolillo DJ: Effects of pioglitazone on platelet p2y12-mediated signalling in clopidogrel-treated patients with type 2 diabetes mellitus. Thromb Haemost 2012;108:930-936.

-35 Berta T, Liu T, Liu YC, Xu ZZ, Ji RR: Acute morphine activates satellite glial cells and up-regulates il-1beta in dorsal root ganglia in mice via matrix metalloprotease-9. Mol Pain 2012;8:18.

36 Moore CS, Ase AR, Kinsara A, Rao VT, Michell-Robinson M, Leong SY, Butovsky O, Ludwin SK, Seguela P, Bar-Or A, Antel JP: P2y12 expression and function in alternatively activated human microglia. Neurol Neuroimmunol Neuroinflamm 2015;2:e80.

-37 Thomas MR, Storey RF: Effect of p2y12 inhibitors on inflammation and immunity. Thromb Haemost 2015;114:490-497.

38 Chen YS, Green CR, Danesh-Meyer HV, Rupenthal ID: Neuroprotection in the treatment of glaucoma--a focus on connexin43 gap junction channel blockers. Eur J Pharm Biopharm 2015;95:182-193.

39 Spray DC, Hanani M: Gap junctions, pannexins and pain. Neurosci Lett 2017.

40 Zhang ZH, Yu Y, Wei SG, Felder RB: Centrally administered lipopolysaccharide elicits sympathetic excitation via nad(p)h oxidase-dependent mitogen-activated protein kinase signaling. J Hypertens 2010;28:806-816.

41 Wei SG, Zhang ZH, Yu Y, Felder RB: Central sdf-1/cxcl12 expression and its cardiovascular and sympathetic effects: The role of angiotensin ii, tnf-alpha, and map kinase signaling. Am J Physiol Heart Circ Physiol 2014;307:H1643-1654.

42 Wei SG, Yu Y, Weiss RM, Felder RB: Endoplasmic reticulum stress increases brain mapk signaling, inflammation and renin-angiotensin system activity and sympathetic nerve activity in heart failure. Am J Physiol Heart Circ Physiol 2016;311:H871-H880.

43 Kobayashi K, Yamanaka H, Fukuoka T, Dai Y, Obata K, Noguchi K: P2y12 receptor upregulation in activated microglia is a gateway of p38 signaling and neuropathic pain. J Neurosci 2008;28:2892-2902. 